\title{
ENSINO DE ARTE NOS ESTADOS UNIDOS E NO BRASIL
}

\section{Proposta de ensino de arte para crianças ressalta aspectos da criação artística, da História da Arte e da análise da obra de arte}

Este artigo pontua dimensões sobre Arte-Educação (ensino da arte) e Arte-Educação baseada em Disciplinas (DBAE). A idéia surgiu após realizarmos um estudo sobre o papel da Arte-Educação na escola norte-americana ${ }^{1}$, cuja origem, fundamentos e objetivos influenciaram o ensino da arte no Brasil, através da proposta Triangular sugerida pela professora Ana Mae T. B. Barbosa e que muitos pensadores denominam de pós-modernismo ${ }^{2}$ no ensino da arte.

Arte-Educação como terminologia já é em si ousada, porque propõe uma unidade ideologicamente diversa - arte e educação que pretende conciliar o papel do professor e do artista, e esta talvez seja a principal questão para o especialista.

Acredita-se que a arte não é mera conseqüência nem resultado de transformações culturais, mas o instrumento de tais modificações, solidificadas em pensamentos divergentes; enquanto que a educação, pelas suas características próprias, baseia-se em pensamentos convergentes.

Primeiramente faz-se necessário romper com o preconceito de que Arte-Educação é arte apenas para crianças, "Arte-Educação é epistemologia da arte e, portanto, é a investigação de como se aprende arte na escola de primeiro grau (Ensino Fundamental, hoje), segundo grau (Ensino Médio), na universidade e na intimidade dos ateliês"3.

\section{ARTE: MERO ORNAMENTO?}

No início do século XIX, arte e educação nos Estados Unidos eram baseadas em princípios filosóficos comuns e os programas de arte eram destinados às jovens da classe alta, que eram instruídas para adquirir "dons" de refinamento e de elite. A arte, portanto, enfatizava uma falsa realização cultural.

Nas escolas públicas, nesse mesmo período, a arte era ensinada com o objetivo de utilidade a algumas profissões, devido ao crescimento industrial, exaltando o desenho geométrico e a perspectiva linear.

Com o advento da Arte Moderna, no início do século XX, começam as transformações nos países do Novo Mundo.

\section{A AUTORA \\ Marisa Tsubouchi da Silva}

Professora da Escolinha de Arte do Colégio Estadual do Paraná.

1. EISNER, E. W. The role of discipline - based art education in America's schools (O papel da disciplina baseada em ArteEducação em escolas americanas). Marina del Rey: Getty Trust, 1988.

2. Pós-modernidade é uma expressão usada no ensino da arte. Reflete um novo tom no discurso modernista, com ênfase na elaboração, na leitura e no contato com a obra de arte reconhecida historicamente.

3. BARBOSA, A. M. T. B. A imagem no ensino da arte: anos oitenta e novos tempos. São Paulo: Perspectiva, 1991. p. 7. 
A exibição da Arte Moderna, conhecida como Armory Show, 1913, nos Estados Unidos, estimulou a exploração da expressão, mas pouco a pouco levou o ensino da arte à elitização completa.

Surgiu então a New Bauhaus (American School de Design), em Chicago; esta foi a primeira manifestação de Arte-Educação, nos Estados Unidos, que deu importância aos objetivos profissionais, à especialização e desenvolvimento do homem em sua totalidade. "Precisamos de especialistas com uma abordagem universal das atividades humanas e um senso de relações dessas atividades entre si"4.

O currículo era baseado na antiga Bauhaus alemã e o objetivo era o desenvolvimento e a educação das faculdades intelectuais e sensoriais, bem como à busca de uma interação enriquecedora entre ambas. "Educação é o caminho que leva alguém a realizar as próprias descobertas e a alcançar sua expressão própria"`. A influência renovadora da New Bauhaus sobre o ensino da arte nos Estados Unidos foi muito grande e repercute até hoje. Contudo, após a Segunda Guerra Mundial, o currículo da Bauhaus sofreu deturpações que comprometeram o ensino da arte.

Instalou-se nas escolas de arte um tecnicismo exagerado e, por outro lado, um laissez-faire ${ }^{6}$ oriundo do abstracionismo e do expressionismo, fortalecendo a abordagem de que a arte se baseava apenas no sentimento, deixando-a marginalizada dentro dos currículos escolares.
Após a década de 50, Josef Albers deu nova racionalidade ao ensino da arte nos Estados Unidos. Para ele, na arte, o mais valioso é ver e pensar com clareza. Ele acreditava que um período de experiência analítica era necessário e que o aluno deveria assumir a tarefa de criar por si mesmo. Com isso, ele conseguiu "dar à gramática visual, valor de expressão"”.

$\mathrm{Na}$ Inglaterra já existia o movimento de conteúdo curricular no ensino da arte, defendido pelo Basic Design Movement. Nos anos 60, Richard Hamilton, Richard Smith, Joe Tilson e Eduardo Paolozzi, na Newcastle University, lançavam as bases teórico-práticas do DBAE, isto é, Arte-Educação Baseada em Disciplinas, trabalho desenvolvido pelo Getty Center of Education in the Arts, influenciados pelo Basic Design Movement e pelas Escuelas al Aire Libre, 1916, no México. Buscava-se, com o desenvolvimento do fazer artístico, a leitura do nacional e de sua História, a solidificação da consciência da cidadania do povo.

O Getty Center of Educacional in the Arts é um centro que prepara professores de arte nos Estados Unidos e no Canadá, através de um ensino que inclui produção de arte, História da Arte, Crítica e Estética.

Para Elliot Eisner, um dos principais arte-educadores daquele país, DBAE é uma metodologia do ensino da arte que corresponde "às quatro mais importantes coisas que as pessoas fazem com a arte. Elas a produzem, elas a vêem, elas procuram entender seu lugar na cultura através do tempo, elas fazem julgamento acerca de sua qualidade"s.

4. MOHOLY NAGY, L. Apud: BARBOSA, A. M. T. B. Teoria e prática da educação artística. 14 ed. São Paulo: Cultrix, 1995. p. 26.

5. MOHOLY NAGY, L. Apud: BARBOSA, A. M. T. B. Teoria e prática... op. cit. p. 26.

6. Laissez-faire ou livre expressão, termo utilizado por Ana Mae Barbosa em A imagem no ensino... op. cit.

7. ARNHEIM. Apud: BARBOSA, A. M. T. B. Teoria e prática... op. cit. p. 30.

8. EISNER. Apud: BARBOSA, A. M. T. B. A imagem no ensino... op. cit. p. 36-37. 


\section{'ROPOSTA TRIANGULAR}

O movimento de Arte Moderna, 1922, jue ocorreu no Brasil acarretou uma grande 'enovação metodológica no campo da ArteZducação, tal como ocorrera nos Estados Jnidos com o Armory Show.

Mário de Andrade e Anita Malfatti inroduziram a defesa da livre expressão para a criança e com isso se criou a idéia de que a arte na educação não se ensina, mas é somente fruto da livre expressão.

Com a criação da Escolinha de Arte do Brasil, 1948, novas concepções se abrem e o objetivo passa a ser o desenvolvimento da capacidade criadora da criança.

Durante muito tempo, mesmo nos Estados Unidos, a criatividade foi confundida com imaginação e o professor era responsável por prover farto material, através do qual a arte pudesse ser expressada.

Os "processos intelectuais e emocionais não se mobilizam automaticamente pelo ato de projeção de formas"9. O intelecto e o sensível não são entidades separadas. É preciso ensinar a ver, a analisar, a investigar.

Em nossas escolas a forte tendência à intelectualização e à assimilação de conteúdos carecia de um currículo que interligasse o fazer artístico à História da Arte e à análise da obra de arte de forma a privilegiar o desenvolvimento da criança, respeitando suas necessidades de expressão. Assim, na década de 80, Ana Mae Barbosa renovou o ensino da arte com a proposta Triangular.

Esta proposta parte do princípio de que através da produção de arte a criança pensa inteligentemente acerca da criação de imagens visuais; a História da Arte ajuda as crianças a entenderem o lugar e o tempo nos quais as obras são situadas; e a análise ou a leitura da obra de arte familiariza a criança com a gramática visual, as imagens fixas e móveis etc.

Um currículo, não importa quão bem planejado esteja, não pode fazer um ótimo trabalho sem a contribuição de professores sensitivos e inteligentes. A educação de crianças sempre exigirá professores sensitivos e profissionalmente capazes de fazer todos os tipos de adaptações e ajustes que são necessários em um contexto particular.

A DBAE, tal como a proposta Triangular, não é uma fórmula mágica, mas sim um conjunto de idéias desenvolvidas a partir de teorias, convicções e fatos sobre o aprendizado infantil, sobre o que é importante ensinar e como o conteúdo pode ser organizado.

Fazer arte no cotidiano da escola, sem perder de vista a relação dialética entre processos sensíveis, emocionais e sociais e o ensino da disciplina e seus processos sensíveis e cognitivos: eis o desafio do professor de Arte-Educação.

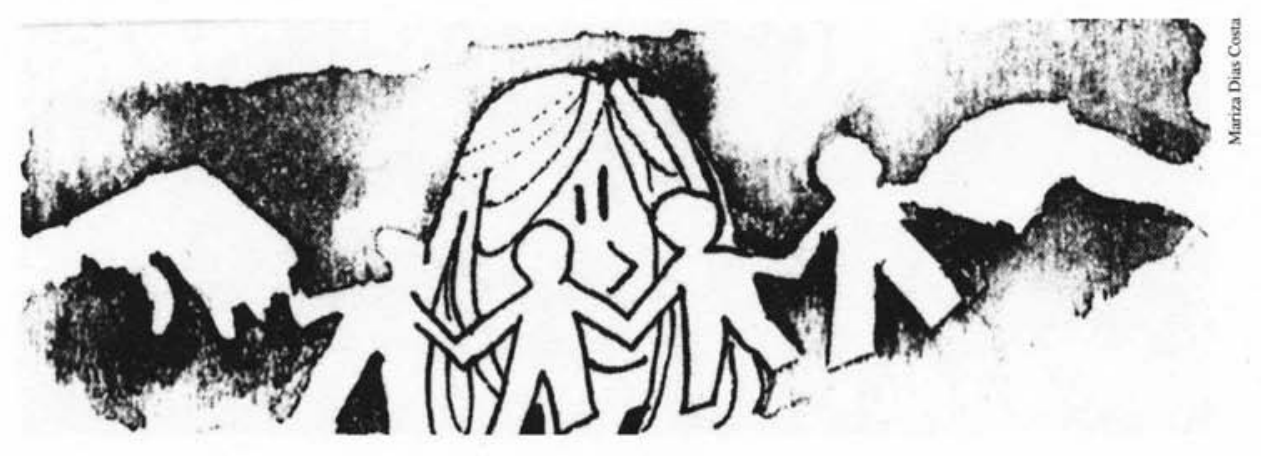

9. BARBOSA, A. M. T. B. A imagem no ensino... op. cit. p. 46. 
Resumo: O artigo trata do desenvolvimento do ensino de arte nos Estados Unidos, através da Arte-Educação Baseada em Disciplinas - DBAE. Destaca como sua influência no Brasil colaborou para a proposição de um currículo que interligasse o fazer artístico à História da Arte e à análise da obra de arte, privilegiando o desenvolvimento da criança e respeitando suas necessidades de expressão. Esta proposta curricular ficou conhecida como proposta Triangular e foi elaborada pela professora Ana Mae Barbosa.

Palavras-chave: Arte-Educação Baseada em Disciplinas, Proposta Triangular, ensino de arte
Abstract: The article deals with the development of art teaching in the United States, through Education Based on Disciplines DBAE. It stresses how its influence on Brazil collaborated to the proposal of a curriculum that integrated doing art with the History of Art and with the analysis of the work of art, privileging the development of the child and respecting the children's needs for expression. This curriculum proposal became known as the Triangular Proposal and was elaborated by Professor Ana Mae Barbosa.

Key words: Art-Education Based on Disciplines, Triangulation, teaching of Art 